\title{
BMJ Open Concealment of type 1 diabetes at work in Finland: a mixed-method study
}

\author{
Pirjo Hakkarainen, ${ }^{1}$ Fehmidah Munir, ${ }^{2}$ Leena Moilanen, ${ }^{3}$ Kimmo Räsänen, ${ }^{1}$ \\ Vilma Hänninen ${ }^{4}$
}

To cite: Hakkarainen $P$, Munir F, Moilanen L, et al. Concealment of type 1 diabetes at work in Finland: a mixedmethod study. BMJ Open 2018;8:e019764. doi:10.1136/ bmjopen-2017-019764

- Prepublication history for this paper is available online To view these files, please visit the journal online (http://dx.doi. org/10.1136/bmjopen-2017019764).

Received 22 September 2017 Revised 29 November 2017 Accepted 11 December 2017

\section{CrossMark}

${ }^{1}$ School of Medicine, Institute of Public Health and Clinical Nutrition, University of Eastern Finland, Kuopio, Finland ${ }^{2}$ School of Sport, Exercise and Health Sciences, Loughborough University, Loughborough, UK ${ }^{3}$ Department of Medicine, Kuopio University Hospital, Kuopio, Finland

${ }^{4}$ Department of Social Sciences, University of Eastern Finland, Kuopio, Finland

Correspondence to

Dr Pirjo Hakkarainen;

pirjoirene.hakkarainen@uef.fi

\begin{abstract}
Objectives To explore the possible reasons for concealing type 1 diabetes (T1D) at work.

Methods The main set of data came from a cross-sectional survey (response rate $49.3 \%$ ), the participants of which were 688 wage earners with T1D. Concealment of T1D was measured by asking respondents have they ever during their working career hidden their diabetes from their (A) colleagues and (B) line manager. Furthermore, semistructured interviews $(n=20)$ were conducted to obtain deeper understanding. Questionnaire data were analysed using logistic regression analyses and qualitative interviews with inductive thematic analysis.
\end{abstract}

Results About $30 \%$ of wage earners with T1D had concealed their condition during their working career from their colleagues and almost $20 \%$ from their line manager. Individuals aged 18-44 years age were more likely to conceal their T1D from their colleagues than older workers during their working career. Not disclosing T1D to the extended family (OR $5.24(95 \% \mathrm{Cl} 2.06$ to 13.35)), feeling an outsider at work (OR $2.47(95 \% \mathrm{Cl} 1.58$ to 3.84$))$, being embarrassed by receiving special attention at work (OR 1.99 (95\% Cl 1.33 to 2.96)) and neglecting treatment at work (OR $1.59(95 \% \mathrm{Cl} 1.01$ to 2.48$)$ ) were all associated with concealment of T1D from colleagues. The youngest age group of 18-24 years were more likely to conceal their T1D from their line managers than the older age groups during their working career. Not disclosing T1D to the extended family (OR 4.41 (95\% Cl 1.72 to 11.32$)$ ), feeling like an outsider at work (OR 2.51 (1.52 to 4.14)) and being embarrassed by receiving special attention at work (OR 1.81 $(95 \% \mathrm{Cl} 1.13$ to 2.91$)$ ) were associated with concealment of T1D from line managers. From the interviews, five main themes related to concealment emerged, expressing fears related to the consequences of telling: (1) being perceived as weak, (2) job discrimination, (3) unwanted attention, (4) being seen as a person who uses their T1D for seeking advantages and (5) losing privacy.

Conclusions A considerable proportion of wage earners with T1D are concealing their diagnosis often because of feelings associated with stigma. Both overemphasis and underestimation of T1D at work by the colleagues or line manager may lead to concealing T1D and may thus be harmful to self-management of T1D. The obstacles in disclosing T1D might be diminished by giving adequate information at the workplace about the condition and its significance.

\section{INTRODUCTION}

Research into the psychosocial aspects of type 1 diabetes (T1D) is growing. ${ }^{1-3}$ However, only
Strengths and limitations of this study

A total of 688 employed respondents participated in our national study, allowing statistically reliable results.

- A strength of our study was the use of quantitative and qualitative methods where the survey identified the prevalence of type 1 diabetes (T1D) concealment and the interviews deepened the understanding of the reasons for concealment.

- The cross-sectional design of our study prevents the interpretation of causality between concealment of T1D and independent variables.

- All measures were self-reported; thus, recall bias may have influenced the results.

- Our results might be extrapolated only to those Western countries, which have similar employment legislation and healthcare systems to Finland.

a few studies have focused on the psychosocial aspects of T1D in working life. ${ }^{45}$ There are several qualitative studies focusing on, for example, self-management of $\operatorname{T}^{1} \mathrm{D}^{67}$ and stigma due to $\mathrm{T}^{1} \mathrm{D}^{89}$ where interviews have brought up work-related psychosocial challenges of T1D. However, both quantitative and qualitative research on T1D with working life as the sole focus is scarce. To the best of our knowledge, there are no previous mixedmethods studies on concealment of T1D at work. In this article, concealing refers to intentionally hiding existence, symptoms and management of T1D.

Despite the advances made both in diabetes care and in supporting persons with T1D at work, evidence suggests that many individuals with T1D are not disclosing their condition to their work colleagues and line managers or do it with caution. Not disclosing T1D or only partially disclosing can affect the individuals' self-management of their condition and, ultimately, their health and well-being. ${ }^{6}{ }^{10} \mathrm{~A}$ number of studies report that non-disclosure of T1D at work is related to perceptions of stigma, discrimination and limited career prospects. ${ }^{9} 11$ An important consequence of not disclosing T1D is avoidance of 
self-managing T1D at work, such as skipping insulin injections. ${ }^{11}$ In contrast, disclosure is related to receiving social support at work, having good psychosocial work ability, as well as relations at work and self-management opportunities at work. ${ }^{12}$

However, while quite much is known about disclosure of diabetes, it is not fully understood why some individuals would choose to conceal their T1D condition in the workplace despite important negative consequences associated with poor self-management of T1D at work. The aim of this article is to explore the possible reasons for concealing T1D at work, which goes beyond the individual simply not telling someone that they have T1D.

\section{MATERIALS AND METHODS \\ Study design}

This is a mixed-method study design ${ }^{13}$ employing quantitative and qualitative research data collection methods. First, we collected quantitative data on concealment of T1D at work by a questionnaire $(n=688)$ as part of a larger research project in Finland. Next, we developed topics for a semistructured qualitative interview schedule using the questionnaire study results and conducted interviews with an independent sample of participants $(n=20)$.

\section{Study 1: questionnaire data}

We sent a postal questionnaire to a random sample of 2500 Finnish working aged people with T1D drawn from the Medication Reimbursement Register of the Social Insurance Institution of Finland, which holds individual-level demographic and medical information on all the Finns with T1D. Random sampling was carried out using the uniform function of SAS for Windows V.9.2. In 2011, there were around 40000 individuals diagnosed with T1D. This random sample, therefore, equalled to $6 \%$ of the Finnish population with T1D. The response rate from the random sample was $49.3 \%$. There were no incentives for taking part in the study. From among the respondents, we selected only those who were in gainful employment during the past 12 months (excluding self-employed) for these analyses $(n=688)$. The questionnaire included items on demographics, diabetes history, diabetes and work, work ability, health, diabetes and current work community, occupational health and safety and diabetes, and occupational health and diabetes. ${ }^{14}$

\section{Measurements}

We measured concealment of T1D by asking respondents 'Have you ever during your working career hidden your diabetes from your colleagues?' and 'Have you ever during your working career hidden your diabetes from your line manager?'. The responses were rated separately on a scale 1-3 (never, sometimes or often) and were dichotomised (never vs sometimes/often) for further analysis. Disclosure to immediate and extended family were measured separately by yes/no options. Work measures included type of work (mental, physical or equally both), employment (permanent/fixed term) and work pattern (regular/irregular). Karasek's ${ }^{15}$ job control (nine items) and job demands (five items) were measured on a scale from 1 to 5 (fully agree to fully disagree). The original indices of job control and job demands were calculated as means of the original items, and the indices were dichotomised with the median as the cutting point. Respondents were asked whether due to their diabetes, they had ever felt like an outsider during their working career (never, sometimes or often); perceived discrimination (never, sometimes or often); were embarrassed by receiving special attention at work (never, sometimes or often); and been prevented from getting a job (yes/no). Respondents were also asked if they had ever during their working career neglected their diabetes treatment during working hours (never, sometimes or often) or had difficulty in accepting their T1D status (no; yes, a little; and yes, a lot). All these ordinal scale responses were dichotomised (never vs sometimes/often) for analysis. Demographic and health questions included age (years), gender (male/female), marital status, educational level, duration of diabetes (years), glycated haemoglobin (HbA1c) level and severe hypoglycaemia events (yes/no).

\section{Statistical analysis}

First, two sets of stepwise logistic regression analyses were conducted for concealment of T1D from (A) colleagues and (B) line managers, as expressed by OR and 95\% CI. Disclosure to family and all demographic, work and health measures were entered as independent variables (total of 20 variables). Second, a further four logistic regression analyses models were performed. For these additional analyses, respondents were split into age groups based on the statistical significance of the differences in concealment between the groups. In the case of concealment from colleagues, the age groups were 18-44 years and 45-64 years. In the case of concealment from line manager, the age groups were 18-24 years and 25-64 years. The aim of these further analyses was to find out possible differences in explanatory variables between age groups. All analyses were carried out in SPSS for Windows, V.21.0; 2012.

\section{Study 2: interviews}

\section{Participants and recruitment}

Twenty Finnish working individuals $(6$ men and 14 women) aged $22-58$ years (mean=39.5, $\mathrm{SD}=12.2$ ) participated in this interview study. They were recruited by the diabetes clinic of the department of endocrinology and diabetology in Kuopio University Hospital. The inclusion criteria were diagnoses of T1D, aged between 18 years and 64 years and in current employment. We used a purposeful sampling frame to ensure variation and balance in the sample by gender, age groups, occupational setting, type of work (physical, mental or equal) and work patterns (regular or irregular work patterns). However, more women volunteered than men. 
A registered nurse at the diabetes clinic identified potential participants by first applying the inclusion criteria to the patient list. Next, the nurse applied the sampling frame to identify a mix of patients. These patients were then approached by the nurse at their next medical appointment at the clinic. The nurse introduced the study to these potential participants and gave a fact sheet and a contact form to those who expressed an interest to take part in the interviews. The nurse kept in regular contact with the researcher to adjust the sampling frame as required.

The potential participants completed and returned the contact form directly to the researcher $(\mathrm{PH})$ via post. The researcher then contacted them by telephone and gave them further details about the research and the interview (interview topics to be covered, approximate length of interview, audio recording, transcription in service and anonymous reporting) and that taking part was entirely voluntary and participants could withdraw at any time. A suitable time and place were arranged for the face-toface interviews with those willing to participate. A written informed consent was completed before the interview. No fee was paid for taking part in the study.

\section{Data collection}

The topics covered by the semistructured interview were based on the preliminary results of the questionnaire survey. The topics were the following: diabetes-related and work-related background, experiences of the relations between T1D and work, current work community and occupational health and safety. In addition, the interviewees were presented with the statistics from the questionnaire data on participants' concealment of T1D and asked to comment on them and discuss possible reasons for concealment. The current article focuses on the themes discussed in this part of the interview.

The aim of the interviews was to elicit narratives of perceived diabetes-related challenges at work. The faceto-face interviews were carried out between March and May 2011 by the main researcher $(\mathrm{PH})$ who is trained in conducting research interviews. Of the 20 interviews, 5 were carried out at the interviewee's home, 4 at the interviewee's workplace and 11 at the interviewer's office in University of Eastern Finland (UEF). The interviews were audio-recorded, and the interviewer made additional notes on her reflections directly after each interview.

\section{Transcription and data analysis}

The audio recordings were transcribed verbatim by a professional transcription service. The interviewer (PH) checked the transcripts against the recordings and anonymised the data. The interviews lasted on average $67 \mathrm{~min}$ (range $37-96 \mathrm{~min}$ ). An inductive thematic analysis ${ }^{16}$ was used to examine the data. The transcripts were read and reread separately by two members of the research group ( $\mathrm{PH}$ and $\mathrm{VH}$ ). First, the researchers picked out the passages that dealt with concealing diabetes and categorised the passages according to the motives ascribed
Table 1 Characteristics of the participants

$\mathrm{n}=688$

\begin{tabular}{|c|c|}
\hline \multicolumn{2}{|l|}{ Gender $(n=684)$} \\
\hline Women & $318(46.5)$ \\
\hline Men & $366(53.5)$ \\
\hline Mean \pm SD age, years $(n=681)$ & $35.4 \pm 12.2$ \\
\hline \multicolumn{2}{|l|}{ Education $(n=688)$} \\
\hline $\begin{array}{l}\text { Basic education (only high school or vocational } \\
\text { course) }\end{array}$ & $155(22.5)$ \\
\hline Vocational school & $237(34.4)$ \\
\hline $\begin{array}{l}\text { Technical or vocational college, or university } \\
\text { of applied sciences }\end{array}$ & $196(28.5)$ \\
\hline University & $100(14.5)$ \\
\hline \multicolumn{2}{|l|}{ Last HbA1c level ${ }^{\star}(n=678)(\%)$} \\
\hline$\leq 60 \mathrm{mmol} / \mathrm{mol}(\leq 7.5)$ & $230(33.9)$ \\
\hline $61-70 \mathrm{mmol} / \mathrm{mol}(7.6 \%-8.5)$ & $233(34.4)$ \\
\hline $71-80 \mathrm{mmol} / \mathrm{mol}(8.6 \%-9.5)$ & $156(23.0)$ \\
\hline$\geq 81 \mathrm{mmol} / \mathrm{mol}(\geq 9.6)$ & $59(8.7)$ \\
\hline \multicolumn{2}{|l|}{ Duration of diabetes ( $n=685$ ) (years) } \\
\hline $0-5$ & $165(24.1)$ \\
\hline $6-10$ & $221(32.3)$ \\
\hline $11-15$ & $266(38.8)$ \\
\hline$\geq 16$ & $33(4.8)$ \\
\hline \multicolumn{2}{|l|}{ Type of work ( $n=683)$} \\
\hline Mental work & $290(42.5)$ \\
\hline Physical work & $171(25.0)$ \\
\hline Mental and physical work (equally) & $222(32.5)$ \\
\hline Mean \pm SD length of employment, years $(n=652)$ & $8.5 \pm 9.5$ \\
\hline \multicolumn{2}{|l|}{ Type 1 diabetes concealed } \\
\hline From colleagues $(n=683)$ & $203(29.7)$ \\
\hline From line manager $(n=686)$ & $123(17.9)$ \\
\hline
\end{tabular}

Data are $\mathrm{n}(\%)$ except where indicated. Missing data were excluded.

*Self-reported.

to concealment. After that, they coded the data independently on the basis of the categorisation. Then the researchers compared and discussed their decisions, ready to revise the categorisation in case of discrepancies. No such discrepancies arose, however.

\section{RESULTS}

\section{Study 1: questionnaire}

The characteristics of the 688 respondents are summarised in table 1 . The mean age of the respondents was 36 years, and $47 \%$ of them were women. A total of $44 \%$ of the respondents were diagnosed with T1D more than 10 years ago. A total of $30 \%$ of the respondents had concealed their diabetes during their working career from their colleagues and $18 \%$ from their line manager. In total, $16 \%$ of the respondents reported having concealed their 
Table 2 A logistic regression analysis of concealment of type 1 diabetes to colleagues or line manager during the respondent's working career

\begin{tabular}{|c|c|c|c|c|}
\hline & \multicolumn{2}{|l|}{ Colleagues $(n=594)$} & \multicolumn{2}{|c|}{ Line manager $(n=596)$} \\
\hline & OR (95\% Cl) & $P$ value & OR (95\% Cl) & $P$ value \\
\hline Age (years) & & 0.019 & & 0.004 \\
\hline $18-24$ & 3.77 (1.42 to 9.97$)$ & 0.008 & $4.23(1.38$ to 12.95$)$ & 0.011 \\
\hline $25-34$ & 3.65 (1.39 to 9.56$)$ & 0.008 & $2.68(0.88$ to 8.23$)$ & 0.084 \\
\hline $35-44$ & 3.23 (1.24 to 8.95$)$ & 0.017 & $1.79(0.55$ to 5.81$)$ & 0.332 \\
\hline $45-54$ & 1.78 (0.61 to 5.18$)$ & 0.288 & 1.23 (0.34 to 4.47$)$ & 0.754 \\
\hline $55-64$ (ref) & 1 & & 1 & \\
\hline \multicolumn{5}{|c|}{ Non-disclosure to extended family } \\
\hline Yes & 5.24 (2.06 to 13.35$)$ & 0.001 & 4.41 (1.72 to 11.32$)$ & 0.002 \\
\hline No (ref) & 1 & & 1 & \\
\hline \multicolumn{5}{|c|}{ Feeling an outsider at work } \\
\hline Yes & 2.47 (1.58 to 3.84$)$ & $<0.001$ & 2.51 (1.52 to 4.14$)$ & $<0.001$ \\
\hline No (ref) & 1 & & 1 & \\
\hline \multicolumn{5}{|c|}{ Embarrassed by receiving special attention } \\
\hline Yes & 1.99 (1.33 to 2.96$)$ & 0.001 & 1.81 (1.13 to 2.91$)$ & 0.014 \\
\hline No (ref) & 1 & & 1 & \\
\hline \multicolumn{5}{|c|}{ Neglected treatment of diabetes at work } \\
\hline Yes & 1.59 (1.01 to 2.48$)$ & 0.044 & - & - \\
\hline No (ref) & 1 & & - & - \\
\hline
\end{tabular}

Missing data were excluded.

diabetes during their working career from both their colleagues and line manager alike.

\section{Results of the stepwise logistic regression}

Of the 20 variables included in the stepwise logistic regression analyses, five variables were retained in the final models. The logistic regression model on concealment from colleagues concluded in five steps (table 2). Individuals in the age group of 18-44 years were more likely to conceal their T1D from their colleagues than older workers during their working career. Not disclosing T1D to the extended family, feeling an outsider at work, being embarrassed by receiving special attention at work and neglecting treatment at work were all associated with concealment of T1D from colleagues.

The model on concealment from the line manager concluded in four steps (table 2). The youngest age group of 18-24 years were more likely to conceal their T1D from their line managers than the older age groups during their working career. Not disclosing T1D to the extended family, feeling like an outsider at work and being embarrassed by receiving special attention at work were associated with concealment of T1D from line managers.

In the further analysis, the colleague model in age groups 18-44 years and $45-64$ years, as well as the line manager model in age groups 18-24 years and 25-64 years revealed that different variables were associated with concealment of T1D at work in different age groups (table 3 ). In the younger group, feeling embarrassed by receiving special attention was strongly associated with concealment. In contrast, for the older group, feeling an outsider in the workplace was the strongest association with concealment.

\section{Study 2: interviews}

All interviewees $(n=20)$ discussed possible reasons for concealment of T1D at work. About a half of them had first-hand experience of concealing. Of those who had not concealed their diabetes, most of them understood why some people may choose to conceal. More than half of the interviewees discussed their own positive experiences of disclosing.

Five main categories of reasons for concealment emerged from the inductive analysis of the interview data. Each of them reflected the interviewees' perceptions of what the consequences of telling at their workplace about their T1D status might be. The first four themes (being perceived as weak, job discrimination, unwanted attention and being seen as a person who uses their T1D for seeking advantages) anticipated other people's attitudes and behaviour and the fifth reflected the person's wish to avoid too close intimacy with others. All of the interviewees discussed at least two out of the five identified kinds of reasons of concealment.

The first kind of reason the interviewees thought might lead to concealment was labelled fear of being perceived as weak or fear of losing status among the workmates. The participants discussed that diabetes is often kept 
Table 3 Four further logistic regression analyses of concealment of type 1 diabetes to colleagues or line manager during the respondent's working career

$\begin{array}{ll}\begin{array}{l}\text { Concealment from colleagues } \\ \text { in the age group of 18-44 years } \\ (n=466) \text { OR }(95 \% \mathrm{Cl})\end{array} & \begin{array}{l}\text { Concealment from line manager } \\ \text { in the age group of 18-24 years } \\ (n=154) \text { OR }(95 \% \mathrm{Cl})\end{array}\end{array}$

$(\mathrm{n}=466)$ OR $(95 \% \mathrm{Cl})$

$P$ value $(n=154)$ OR $(95 \% \mathrm{Cl})$

$P$ value

Embarrassed by receiving special attention

$\begin{array}{llll}\text { Yes } & 2.23(1.46 \text { to } 3.40) & <0.001 & 3.16(1.52 \text { to } 6.60) \\ \text { No (ref.) } & 1 & 1 & 0.002\end{array}$

Feeling an outsider at work

\begin{tabular}{|c|c|c|c|c|}
\hline Yes & 2.20 (1.36 to 3.55$)$ & 0.001 & - & - \\
\hline No (ref.) & 1 & & - & - \\
\hline & $\begin{array}{l}\text { Concealment from colleagues } \\
\text { in the age group of } 45-64 \text { years } \\
(n=128) \text { OR }(95 \% \mathrm{Cl})\end{array}$ & & $\begin{array}{l}\text { Concealment from line manager } \\
\text { in the age group of } 25-64 \text { years } \\
(n=442) \text { OR }(95 \% \mathrm{Cl})\end{array}$ & \\
\hline
\end{tabular}

\begin{tabular}{|c|c|c|c|c|}
\hline \multicolumn{5}{|c|}{ Duration of diabetes } \\
\hline 0-10years & 3.79 (1.22 to 11.83$)$ & 0.022 & - & - \\
\hline$>10$ years (ref.) & 1 & & - & - \\
\hline \multicolumn{5}{|c|}{ Feeling an outsider at work } \\
\hline Yes & 8.84 (2.71 to 28.91$)$ & $<0.001$ & 4.16 (2.35 to 7.38$)$ & $<0.001$ \\
\hline No (ref.) & 1 & & 1 & \\
\hline \multicolumn{5}{|c|}{ Non-disclosure to extended family } \\
\hline Yes & 42.27 (6.26 to 285.51$)$ & $<0.001$ & 3.82 (1.40 to 10.42$)$ & 0.009 \\
\hline No (ref.) & 1 & & & \\
\hline
\end{tabular}

For these additional analyses, respondents were split into age groups based on results of the first two logistic regression analyses models. Missing data were excluded.

hidden because telling someone about it at work would make that person seem weak and inferior to others. Appearing as weak may be felt as causing loss of status among the work mates. 'You feel you are weak and you don't want to show your weakness to your pack' (man, aged 27). Altogether, people were seen as not willing to differ from the others, especially in a negative way. 'It's perhaps just that I wanted to be like everybody else' (man, 49). It was also mentioned that T1D may be seen as an indication of a more general personal fault. Some interviewees used the social scientific word stigma to refer both to losing status among the colleagues and to being at risk of discrimination. 'I think [by not disclosing] you can avoid being stigmatized' (woman, aged 53).

The second kind of reason for concealment told about by the interviewees was related to the fear of discrimination. Several examples were given of the ways in which being open about one's diabetes could hinder the individual from getting a job or a promotion or could increase the probability of getting laid off. Both young and middle-aged interviewees talked about discrimination: 'If I left this job, I don't know if, due to my diabetes, I could get a new job. This thought is absolutely horrifying!" (woman, aged 29). Some interviewees mentioned possible reasons for discrimination: a person with T1D might be seen as one who is often on sick leaves or is prone to accidents and who is 'in the end more expensive'. (woman, aged 40).
Reluctance to receive special attention was the third category of reasons for concealment that emerged in the interviews. The interviewees gave examples of the ways in which other people had made a fuss, been overprotective or patronising after hearing about the interviewees' diabetes. Irrespective of whether this had been benevolent or malevolent, it was felt as awkward. Lack of up-to-date knowledge about diabetes was seen as the main reason for overprotection.

My colleagues might come every two hours to ask how I feel and if I am okay. If they see me buying chocolate, they might go and tell my supervisor that my blood sugar is swinging. (Woman, aged 29)

Fear of being seen as a person who uses their T1D for seeking advantages was yet another category of reasons for concealment brought up by the interviewees. The special arrangements, such as taking regular meal breaks to manage diabetes were sometimes not understood as necessary, as some people did not know about the seriousness of the illness. It might be that people are mixing up type 1 and type 2 diabetes, and there is a real lack of understanding of T1D.

I feel that some of my colleagues thought that diabetes is just a pretext to being allowed to have meal breaks every fourhours. As if it was only something 
I'd like to have although it was something I had to have. There is no reason for envy. (Woman, aged 26)

The final category of reasons for concealment was related to losing privacy, that is, a perception that illnesses are private matters that should only be disclosed to close people. The wish to keep the illness to oneself was seen as understandable especially when the relations between workmates are distant, when the worker has not quite made the illness as a part of their identity and when the person is generally reserved as a person.

... Of course, illness is always a personal matter, and not everybody wants to make it public. (Woman, aged 51)

... Not everything is everybody's business. (Man, aged 26)

In connection with discussing the reasons for concealment, the interviewees usually mentioned the risk associated with hypoglycaemia events if nobody around knows how to deal with it.

There's a real risk of losing your life if you get a hypoglycaemia and nobody knows. You might even die in the worst case. (Woman, aged 49)

Also, self-management of T1D - having regular meal breaks, measuring blood glucose levels, injection and visits to a doctor-was seen as difficult for one who tries to conceal their condition.

When asked in what kind of workplace disclosing one's illness would be easy, the interviewees emphasised openness, trust and mutual caring of each other as important factors favouring disclose. One interviewee said it would be helpful if the workers were always evaluated on the basis of how they do their job instead of on the basis of their personal features.

\section{DISCUSSION}

As far as we know, this is a first population-based study to report figures of concealment of T1D from colleagues and line managers at work places. In this article, concealing refers to intentionally hiding the existence, symptoms and management of T1D. In our survey results, about one in three had sometimes or often concealed their T1D from their colleagues, one in five from their line manager and one in six from both colleagues and line manager during their working career. This is noteworthy, because colleagues may be the first ones to notice a hypoglycaemia event and to offer help when needed. ${ }^{8}$ In addition, the line manager can support a worker with T1D to manage their condition effectively at work if they knew about a worker's T1D status. ${ }^{6}$

Young workers were more likely to have concealed their T1D than older ones from both colleagues and line manager. This could be interpreted as indicating harsher competition for jobs and proceeding in a career between younger workers in the current working life. It is also obvious that young adults being in the beginning of their working career have more to lose than older people. Although the effect of fear of discrimination did not reach significance in the quantitative part of the study, the theme of discrimination was often brought up by the interviewees-young and older alike. To the best of our knowledge, there are no previous studies concerning concealment of T1D among young workers.

We found by regression analysis that those who had not disclosed their T1D to their extended family were more likely to conceal their condition from colleagues and line manager. This suggests that some workers may choose to keep their condition hidden from everyone outside their closest circle of people, which was also discussed in the interviews. In addition, those who felt like an outsider at work due to their T1D were more likely to conceal their condition from colleagues and line manager. In the same line, some of the interviewees said that unopen and strained working relationships at work make it difficult to reveal one's T1D. This emphasises the importance of the quality of relationships in the workplace. ${ }^{717}$ If working relationships are strained and there is little interpersonal trust or a negative workplace climate, then workers are more likely to conceal their condition at work. ${ }^{6}$ This has been confirmed in a Danish study among workers with type 2 diabetes. ${ }^{18}$ Employers and managers have an important role in developing an inclusive working environment. ${ }^{17}$ Thus, they should take working relationships into account when developing workplace practices.

Although openness with employers could be encouraged, it is important to remember that disclosure of one's chronic condition is a highly private and confidential decision, ${ }^{17} 19$ and there should be no pressure to do it. In Finland, an employer can ask an applicant about their health status during a job interview only if there is a legal reason to do so, that is, if a health condition may potentially impact job safety. ${ }^{20}$ In addition, the Non-discrimination Act $(1325 / 2014)^{21}$ promotes equality and prevent discrimination in the workplaces.

Embarrassment caused by receiving special attention at work due to T1D was associated with concealment of T1D from colleagues and line manager. The theme 'unwanted attention' was also found in the interviews. Giving special attention was seen as an over-reaction to the risks related to the condition. However, some of the interviewees felt that the risks related to T1D could be underestimated, which could result in seeing a person with T1D as one who uses their condition for seeking unwarranted advantages. As far as we know, there are no previous studies reporting this kind of results.

In general, concealment of T1D from colleagues was associated with neglecting self-management of T1D at work. If a person conceals their T1D from a colleague, it is difficult to self-manage their condition effectively at work place. This may lead to keeping blood sugar levels higher than optimal to manage at work as found in a previous study from UK. ${ }^{7}$ We reported in our previously published study that work-related diabetes distress, such 
as worry and exhaustion in reconciling work with T1D, was strongly associated with keeping blood glucose level high at work. ${ }^{14}$ In addition, it has been shown that young workers with T1D experience time pressure at their work and therefore they sometimes neglect or delay self-management activities at work. ${ }^{5}$ As both concealment and time pressure among young workers with T1D hinder their self-management activities at work, special attention should be focused on supporting them for avoiding longterm complications and diminishing of work ability.

One of the often discussed reasons for concealing one's T1D at the workplace was fear of discrimination, which could restrict one's career development and even lead to unemployment. This supports a previous qualitative study that also found those with T1D, who did not disclose their condition at work, gave the reason as fear of being discriminated against, which could harm their working career. ${ }^{9}$ Our findings also relate to the finding of the study of Polish seafarers with T1D who were not allowed to work at sea and who concealed their condition from healthcare and from their colleagues and worked on seagoing vessels. ${ }^{22}$ Another frequently mentioned reason for concealing one's T1D was reluctance to appear as a weaker or inferior person than the others. This kind of reluctance to give an impression of weakness has previously been obtained among adolescents, young adults and adults with T1D. ${ }^{923} 24$

Both above-mentioned reasons for concealment, fear of discrimination and fear of being seen as weak, can be subsumed under the term 'stigma'. Social disadvantages of poor health are often described with the concept of stigma, that is, disqualification of full social acceptance. ${ }^{25}$ Health-related stigma may lead to anticipated or actual experience of stereotyping, exclusion, blame and discrimination. ${ }^{26}{ }^{27}$ Although T1D is not necessarily considered a very stigmatising condition by the general public, people with the condition nevertheless feel stigmatised by it. ${ }^{28} 29$ In some societies, for example, China, the stigma is especially high. ${ }^{11}$ Additionally, a lack of adequate knowledge of T1D causes transposition between T1D and type 2 diabetes and a new type of stigmatisation including the conception that the condition is self-inflicted. ${ }^{930}$

\section{Strengths and limitations}

To our knowledge, this is the first study to investigate concealment of T1D at a national level. One of the strengths of the study was that 688 employed respondents with T1D participated in our study, allowing statistically reliable results.

Another strength of our study was the combination of quantitative and qualitative methods. This had several benefits. Carrying out the interviews after the first stage of analysis of the survey data made it possible to ask the interviewees to comment on the finding that a great proportion of people with T1D choose to conceal their condition in the workplace. The interviews deepened the understanding of the reasons of concealment that had been asked in the survey and revealed new reasons that were not covered by the survey. Moreover, similar results obtained by different methods increased the validity of the findings.

A number of study limitations need to be considered. First, this study was cross-sectional and therefore the interpretation of causality is not possible. Second, the response rate was only $49 \%$. However, the respondents represented working-aged Finns with T1D as the sample was not biased in terms of demographic distributions. There was a small difference in the gender distribution between the respondents and non-respondents (proportion of women participating more than men). The distributions of the age groups and residential provinces were similar in both groups (dispersion about 2\%). The final sample represented workers from different organisations and occupations. ${ }^{31}$ In recruiting for the qualitative interviews, more women volunteered than men, and we had to stop data collection as we reached the end point for the recruitment period. This can be considered as a limitation, although women's over-representation is usual in this kind of research. ${ }^{32}$ In the interviews, the interviewees did not necessarily report the reasons of their own concealment but their views on why other people choose to conceal their condition. The interviews were carried out only in one city, which can be considered as a limitation in our study. However, Kuopio is a middle-sized city and located middle in Finland, and the demographics of this city is similar to other cities in Finland. Moreover, all measures were self-reported; thus, recall bias may have influenced the results. In addition, our results might be extrapolated only to those Western countries, which have same kind of employment legislation and healthcare systems to Finland.

\section{CONCLUSION}

Concealment of T1D at work was common enough to warrant serious attention. On the basis of our findings, it could be suggested that both overemphasis and underestimation of the consequences of T1D in the workplace may lead to concealing and thus may be harmful to self-management and reconciling work and T1D. Both overemphasis and underestimation might be diminished by increasing up-to-date knowledge about the condition among the workmates and supervisors. However, the fear of discrimination is difficult to overcome if there is a real risk of losing opportunities because of illness.

Young workers were more likely than older ones to conceal their T1D in their work community. Concealing may be especially harmful for their health as they have a long working life ahead of them. Thus, special attention should be focused on supporting young workers with T1D.

Acknowledgements The authors gratefully acknowledge all those who participated in this study by filling out and returning the questionnaire, RN Erja Huttunen for her assistance with patient recruitment and all those who participated in the interview study. 
Contributors PH, LM, KR and VH designed the study and planned the data collection. PH and FM researched the survey data, performed the statistical analyses and wrote and edited the manuscript; $\mathrm{PH}$ and VH researched the interview data, performed the thematic analyses and wrote and edited the manuscript; LM and KR helped to interpret the results and edited the manuscript. All authors have read this manuscript, and the requirements for authorship have been met. VH is the guarantor of this work. She had full access survey and interview data in this study. She takes responsibility for the integrity of the data and the accuracy of the data analysis.

Funding PH was supported by grants from The Finnish Work Environment Fund (No. 111166) and The Finnish Diabetes Association.

Competing interests None declared.

Patient consent Obtained.

Ethics approval The Research Ethics Committee of the Northern Savo Hospital District reviewed and approved the research protocol (18//2010).

Provenance and peer review Not commissioned; externally peer reviewed.

Data sharing statement The datasets generated during and/or analysed during the current study are not publicly available due to other ongoing research projects using the material but are available from the corresponding author on reasonable request.

Open Access This is an Open Access article distributed in accordance with the Creative Commons Attribution Non Commercial (CC BY-NC 4.0) license, which permits others to distribute, remix, adapt, build upon this work non-commercially, and license their derivative works on different terms, provided the original work is properly cited and the use is non-commercial. See: http://creativecommons.org/ licenses/by-nc/4.0/

(C) Article author(s) (or their employer(s) unless otherwise stated in the text of the article) 2018. All rights reserved. No commercial use is permitted unless otherwise expressly granted.

\section{REFERENCES}

1. Balfe M, Doyle F, Smith D, et al. What's distressing about having type 1 diabetes? A qualitative study of young adults' perspectives. BMC Endocr Disord 2013;13:25.

2. Fisher L, Hessler D, Polonsky W, et al. Diabetes distress in adults with type 1 diabetes: Prevalence, incidence and change over time. $J$ Diabetes Complications 2016;30:1123-8.

3. Hempler NF, Joensen LE, Willaing I. Relationship between social network, social support and health behaviour in people with type 1 and type 2 diabetes: cross-sectional studies. BMC Public Health 2016;16:198.

4. Weijman I, Ros WJ, Rutten GE, et al. Frequency and perceived burden of diabetes self-management activities in employees with insulin-treated diabetes: relationships with health outcomes. Diabetes Res Clin Pract 2005;68:56-64.

5. Balfe M, Brugha R, Smith D, et al. Why do young adults with type 1 diabetes find it difficult to manage diabetes in the workplace? Health Place 2014:26:180-7.

6. Bose J. Promoting successful diabetes management in the workplace. Int J Workplace Health Manag 2013;6:205-26.

7. Ruston A, Smith A, Fernando B. Diabetes in the workplace diabetic's perceptions and experiences of managing their disease at work: a qualitative study. BMC Public Health 2013;13:386.

8. Patel N, Eborall H, Khunti K, et al. Disclosure of type 1 diabetes status: a qualitative study in a mixed South Asian population in central England. Divers Equal Health Care 2011;8:217-23.
9. Browne JL, Ventura A, Mosely K, et al. 'I' m not a druggie, l' m just a diabetic': a qualitative study of stigma from the perspective of adults with type 1 diabetes. BMJ Open 2014;4:e005625.

10. Shaban C. Psychological themes that influence self-management of type 1 diabetes. World J Diabetes 2015;6:621-5.

11. Jaacks LM, Liu W, Ji L, et al. Type 1 diabetes stigma in China: a call to end the devaluation of individuals living with a manageable chronic disease. Diabetes Res Clin Pract 2015;107:306-7.

12. Hakkarainen $P$, Moilanen $L$, Hänninen V, et al. Disclosure of type 1 diabetes at work among Finnish workers. Diabet Med 2017;34:115-9.

13. Teddlie C, Tashakkori A. Foundations of mixed methods research. Integrating quantitative and qualitative approaches in the social and behavioral sciences: SAGE Publications, Inc, 2009.

14. Hakkarainen $P$, Moilanen $L$, Hänninen V, et al. Work-related diabetes distress among Finnish workers with type 1 diabetes: a national cross-sectional survey. J Occup Med Toxicol 2016;11:11.

15. Karasek R, Brisson C, Kawakami N, et al. The Job Content Questionnaire (JCQ): an instrument for internationally comparative assessments of psychosocial job characteristics. J Occup Health Psychol 1998;3:322-55.

16. Braun V, Clarke V. Using thematic analysis in psychology. Qual Res Psychol 2006;3:77-101.

17. von Schrader $S$, Malzer V, Bruyère $S$. Perspectives on disability disclosure: the importance of employer practices and workplace climate. Employ Respons Rights J 2014;26:237-55.

18. Olesen K, Cleal B, Skinner T, et al. Characteristics associated with non-disclosure of type 2 diabetes at work. Diabet Med 2017:34:1116-9.

19. Lee SM, Lim LC, Koh D. Stigma among workers attending a hospital specialist diabetes clinic. Occup Med 2015;65:67-71.

20. Ministry of Labour Finland. Act on the protection of privacy in working life (759/2004). 2004. http://www.finlex.fi/en/laki/kaannokset/ 2004/20040759 (accessed 16 Aug 2017).

21. Ministry of Justice, Finland. Non-discrimination act (1325/2014). 2014. http://www.finlex.fi/fi/laki/kaannokset/2014/en20141325 (accessed 16 Aug 2017).

22. Jaremin B, Szymańska K, Chełmińska K. Diabetes and work at sea: has everything been already settled? Article for discussion. Int Marit Health 2005;56:94-100.

23. Abdoli S, Abazari P, Mardanian L. Exploring diabetes type 1-related stigma. Iran J Nurs Midwifery Res 2013;18:65-70.

24. Commissariat PV, Kenowitz JR, Trast J, et al. Developing a personal and social identity with type 1 diabetes during adolescence: a hypothesis generative study. Qual Health Res 2016;26:672-84.

25. Goffman E. Stigma: notes on the management of spoiled identity. Englewood Cliffs, NJ: Prentice Hall, 1963.

26. Link BG, Phelan JC. Conceptualizing stigma. Annu Rev Sociol 2001;27:363-85.

27. Weiss MG, Ramakrishna J, Somma D. Health-related stigma: rethinking concepts and interventions. Psychol Health Med 2006;11:277-87.

28. Schabert J, Browne JL, Mosely K, et al. Social stigma in diabetes : a framework to understand a growing problem for an increasing epidemic. Patient 2013;6:1-10.

29. Liu NF, Brown AS, Younge MF, et al. Stigma in people with type 1 or type 2 diabetes. Clin Diabetes 2017;35:27-34.

30. Anderson-Lister G, Treharne GJ. 'Healthy' individuals' perceptions of type 1 and type 2 diabetes cause and management: a thinkaloud' mixed-methods study using video-based vignettes. J Health Psychol 2014;19:1371-81.

31. Hakkarainen $\mathrm{P}$, Sund R, Arffman M, et al. Working people with type 1 diabetes in the Finnish population. BMC Public Health 2017;17:805.

32. Markanday S, Brennan SL, Gould H, et al. Sex-differences in reasons for non-participation at recruitment: Geelong Osteoporosis Study. BMC Res Notes 2013;6:104. 